\title{
Oxidation of Aldoses Contained in Softwood Hemicellulose Acid Hydrolysates into Aldaric Acids under Alkaline or Noncontrolled pH Conditions
}

\author{
Elie Derrien, ${ }^{\dagger \dagger}$ Mohammed Ahmar, ${ }^{\S}$ Emilie Martin-Sisteron," Guy Raffin," Yves Queneau, ${ }^{\S}$ \\ Philippe Marion, ${ }^{\ddagger}$ Marlène Beyerle, ${ }^{\perp}$ Catherine Pinel, ${ }^{\dagger}$ and Michèle Besson* ${ }^{\dagger}$ 이 \\ ${ }^{\dagger}$ Univ Lyon, Univ Claude Bernard, CNRS, IRCELYON, UMR 5256, 2 Avenue Albert Einstein, 69626 Villeurbanne, France \\ ${ }^{\ddagger}$ SOLVAY Research and Innovation Center of Lyon, 69192 Saint Fons, France \\ ${ }^{\S}$ Univ Lyon, Univ Claude Bernard, INSA Lyon, CPE Lyon, ICBMS, UMR 5246, 20 Avenue Albert Einstein, 69621 Villeurbanne, \\ France \\ "Univ Lyon, Univ Claude Bernard, CNRS, ENS de Lyon, ISA, UMR 5280, 5 rue de la Doua, 69100 Villeurbanne, France \\ ${ }^{\perp}$ Novasep Process, 5 chemin du Pilon, 01700 St Maurice de Beynost, France
}

\begin{abstract}
The hemicellulose-derived aqueous solution of C6 and C5 sugars (D-mannose, D-galactose, D-glucose, D-xylose, Larabinose), obtained from the extraction and hydrolysis of the hemicellulosic polymers in softwoods prior to the production of pulp, was catalytically converted to the corresponding aldaric acids under alkaline $(\mathrm{Pt} / \mathrm{C})$ or native $\left(\mathrm{Au}-\mathrm{Pt} / \mathrm{ZrO} \mathrm{O}_{2}\right)$ aqueous conditions with air. The inhibiting effect of some residual impurities and degraded compounds in the hydrolysate was confirmed, such as colored unsaturated compounds and 5-hydroxymethylfurfural. A combined purification process consisting of filtration, demineralization by ion-exchange resins, evaporation, and active carbon treatment of the raw aqueous-stream gave a purified hydrolysate of aldoses that was oxidized to hexaric and pentaric acids. The yields were close to those of a synthetic solution of the pure sugars with the same distribution. The yields of aldaric acids accounted for ca. $50 \%$ of hexaric acids and up to $70 \%$ of pentaric acids.
\end{abstract}

\section{INTRODUCTION}

Lignocellulosic biomass composed of carbohydrate polymers (cellulose, hemicelluloses) and a complex aromatic polymer (lignin) represents an abundant and cheap source of sugars for the production of many chemicals. The cellulosic fraction currently has a high value and is mainly used to produce paper and cellulosic polymers, or bioethanol. The hemicellulosic part, which is the second most abundant biopolymer representing typically $25-35 \%$ of softwood (dry weight basis), is not currently utilized to its maximum potential. For instance, in the Kraft pulping technology of wood, hemicelluloses are degraded during the cooking process used to extract the cellulose fibers; the residual processing black liquor containing the lignin and the hemicelluloses fragments is ultimately burned for energy production. Therefore, increased attention is being placed on a better utilization of hemicelluloses: as feedstock for bioethanol, as raw material for various biopolymers, or by converting them into sugar monomers, which can in turn be further upgraded into higher value products. $^{1-6}$ In recent years, selective extraction of the hemicelluloses from wood by pretreatment of wood chips prior to pulping has gained increased importance in the biorefinery concept. ${ }^{6-8}$ The biorefinery aims at utilizing the whole biomass for different products and maximizing economic return.

Compared to the other components, and due to their lower degree of polymerization and the presence of branched side groups, hemicelluloses are quite easily hydrolyzed to the 
Scheme 1. Synthesis of the Noncommercial Disodium Aldarates As Illustrated for D-Mannarate

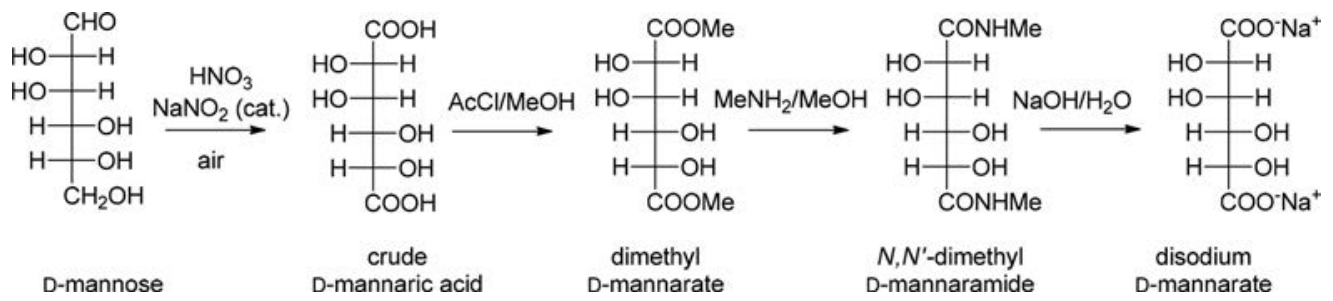

monosugars, the hexoses (D-mannose, D-galactose, D-glucose) as well as the pentoses (D-xylose and L-arabinose). ${ }^{9}$ Among the various pretreatment methods, hot water autohydrolysis and dilute sulfuric acid posthydrolysis under moderate temperature $\left(120-160{ }^{\circ} \mathrm{C}\right)$ has proven to be adequate for selective dissolution of the sugars in hemicelluloses, without significant degradation of the cellulose fibers and with little sugar decomposition. ${ }^{10}$ The extracted wood chips can still be used for pulp production without any impact on pulp quantity and quality, whereas the extracted sugar monomers in the separated hydrolysate can be further converted into high value-added compounds.

The present work addresses the catalytic oxidation with air of the aldoses in the sugar rich aqueous liquor, separated after prehydrolysis of softwood hemicelluloses with diluted sulfuric acid. $^{10}$ The oxidation to the corresponding aldaric acids involves a selective double oxidation of both the aldehyde group as well as the terminal hydroxyl group of the aldoses. The sugar diacids are currently produced on a small scale, but are considered to have great potential. Glucaric acid, derived from glucose, has been ranked as a "top value-added chemical" from biomass. ${ }^{11}$ It is a promising raw material for polymers, as well as detergent builder, chelating agent, deicing agent, and corrosion inhibitor. $^{12-14}$ Its derivatives have also been studied for therapeutic purposes. ${ }^{15,16}$ Aside from glucaric acid, the other carbohydrate diacids (mannaric, galactaric or mucic, xylaric, and arabinaric acids) could also be used to make a range of bioproducts, ${ }^{17}$ and a class of polymers referred as polyhydroxypolyamides, $^{18-22}$ or silicon polyamides. ${ }^{23}$ Oxidation of the aldoses to the corresponding aldaric acids can be conducted using nitric acid, ${ }^{14,24-30}$ TEMPO or 4-acetylamino-TEMPO mediated oxidation in aqueous solutions at high $\mathrm{pH}$ of 1112. ${ }^{31}$ Aldaric acids have also been obtained by catalytic oxidation with oxygen or air. Metallic or bimetallic noble metal catalysts under basic conditions, ${ }^{32-39}$ or without need of base addition ${ }^{40-43}$ have been employed for producing selectively glucarate or glucaric acid.

In our earlier studies, the oxidation of glucose was performed in alkaline aqueous solutions to glucarate over $\mathrm{Pt} / \mathrm{C}^{37}$ or in native aqueous solutions over $\mathrm{AuPt} / \mathrm{ZrO}_{2}{ }^{43}$ These procedures involved the formation of numerous side-products, but resulted in yields over $50 \%$ in batch reactors. We also examined the influence of potential contaminants of the hydrolysates, including residual sulfuric acid, furans, phenolics, weak acids, and oligosaccharides. Indeed, during hydrolysis in acidic medium, degradation of pentoses to furfural and hexoses to 5-hydroxymethyl furfural (HMF), release of acetic acid from Oacetyl groups in the polysaccharides, formation of soluble lignin-derived phenolics, and incomplete hydrolysis may occur. Among them, furanic and phenolic derivatives were shown to be inhibitors of the catalytic oxidation reaction under both operating conditions, suggesting that the hydrolysates will certainly not be used directly and they will have to be purified prior to the oxidation reaction.

The principal goal of this research was to perform the catalytic oxidation of the sugars in the hemicelluloses hydrolysate, separated after autohydrolysis with hot water and posthydrolysis with diluted $\mathrm{H}_{2} \mathrm{SO}_{4}$ of softwood chips, to a mixture of the corresponding aldaric acids. The reactions of synthetic solutions of the different aldoses were performed, separately or in mixture, in the presence of $\mathrm{Pt} / \mathrm{C}$ with $\mathrm{pH}$ control at 9, or in the presence of $\mathrm{AuPt} / \mathrm{ZrO}_{2}$ without $\mathrm{pH}$ control, before the evaluation of the performance of the catalysts for the oxidation of the hydrolysate purified to various degrees.

\section{EXPERIMENTAL SECTION}

2.1. Materials and Methods. Wherever possible, sugars, aldaric acids, and other chemicals were purchased from Alfa Aesar or SigmaAldrich at the highest purity obtainable ( $>98 \%)$. The synthesis of some noncommercial aldarates was necessary for identification and quantification by chromatography (vide infra and the Supporting Information).

The two-step hydrolysis of the pinewood chips from a French pulp mill by hot water followed by $5 \mathrm{~g} \mathrm{~L}^{-1}$ sulfuric acid was carried out by Pagora at $160^{\circ} \mathrm{C}$, using a liquor to wood ratio of $4 .^{10}$ The softwood hemicelluloses primarily consisting of galactoglucomannans and some arabinoglucuroxylans were thus hydrolyzed to their primary components. The resulting raw hydrolysate was filtered on $1.2 \mu \mathrm{m}$ filter using a Büchner funnel to remove suspended solids, and was concentrated by vacuum evaporation. The HPLC analysis and purification of hydrolysate samples were carried out at Novasep. The purification included an ion-exchange demineralization operated in columns (Novasep resins XA3112 and XA7111MB) and a granulated active carbon (GAC) treatment performed in stirred batch. The concentration of monosaccharides in the resulting evaporated acidic solution ( $\mathrm{pH} 0.7$ ) was around $46 \mathrm{~g} \mathrm{~L}^{-1}$. It contained mainly mannose, glucose, galactose, xylose, and arabinose. Hexoses were responsible of 72 wt $\%$ of its sugar composition, while pentoses represented 28 wt \%. The liquor contained also diverse degradation products including acetic acid, furans (mainly 5-hydroxymethylfurfural), oligosaccharides, lignin degraded phenolics. Residual inorganic salts (conductivity $12 \mathrm{mS} \mathrm{cm}^{-1}$, measured with a WTW LF conductimeter) were also present in the hydrolysate after filtrationevaporation.

2.2. Synthesis of Disodium Aldarates. Dipotassium D-glucarate and D-galactaric acid (mucic acid) were commercially available. Disodium D-mannarate, D-xylarate, and D-arabinarate, as well as Daltrarate were synthesized by a multistep reaction from the aldoses via dimethylamide intermediate, based on protocols described in the literature (Scheme 1). ${ }^{29,44,45}$ The synthesis and characterization by ${ }^{1} \mathrm{H}$ and ${ }^{13} \mathrm{C}$ NMR, and high-resolution mass spectrometry (HRMS) are described in the Supporting Information.

2.3. Preparation of $\mathrm{Pt} / \mathrm{C}$ and $\mathrm{AuPt} / \mathrm{ZrO}_{2}$ Catalysts. A $4.7 \% \mathrm{Pt} /$ $\mathrm{C}$ catalyst was prepared via wet impregnation and liquid phase reduction by formaldehyde and $\mathrm{KOH}$ using the previously reported procedure. ${ }^{37}$ The $3.5 \% \mathrm{Au}-3.5 \% \mathrm{Pt} / \mathrm{ZrO}_{2}$ catalyst was prepared by wet impregnation with an aqueous solution of $\mathrm{HAuCl}_{4}$ and $\mathrm{H}_{2} \mathrm{PtCl}_{6}$ and using $\mathrm{NaBH}_{4}$ as the reducing agent, as previously reported. ${ }^{43}$ 

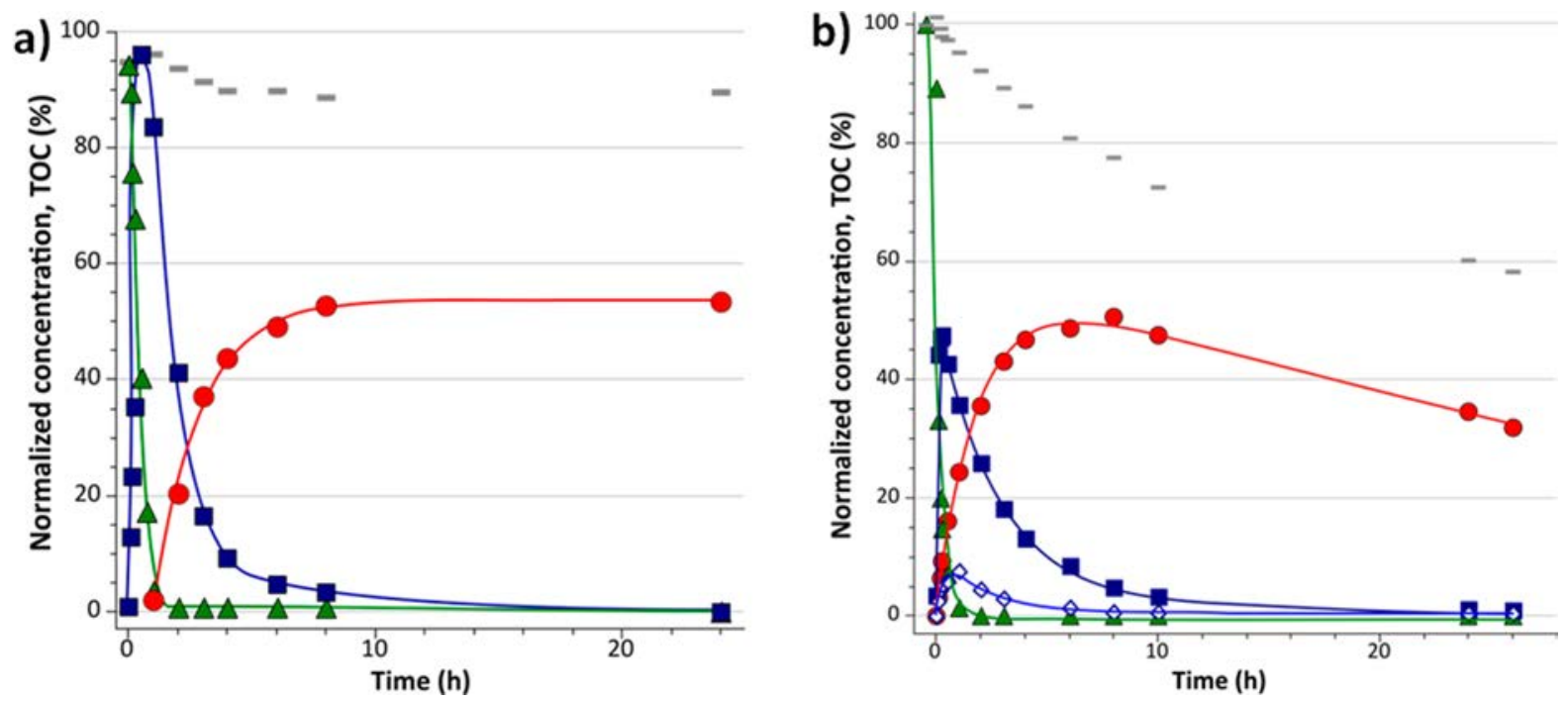

Figure 1. Concentration profiles during oxidation of glucose to (a) glucarate over $3 \% \mathrm{Pt} / \mathrm{C}$ or (b) glucaric acid over $3.5 \% \mathrm{Au}-3.5 \% \mathrm{Pt} / \mathrm{ZrO} 2 . \mathrm{Reaction}$ conditions: (a) $[\text { glucose }]_{0}=0.25 \mathrm{M}$, glucose $/ \mathrm{Pt}$ molar ratio $157, \mathrm{~T}=60^{\circ} \mathrm{C}, 0.5 \mathrm{~L} \mathrm{~min}{ }^{-1}$ air, $\mathrm{pH} 9$; (b) $[\text { glucose }]_{0}=0.25 \mathrm{M}$, glucose $/ \mathrm{metal}=80, T=$ $100{ }^{\circ} \mathrm{C}, 40$ bar of air. $(\boldsymbol{\Lambda})$ glucose, $(\boldsymbol{\square})$ gluconate or gluconic acid, $(\diamond)$ guluronic acid, $(\boldsymbol{\bullet})$ glucarate or glucaric acid, $(-)$ TOC.

Characterization of these catalysts were described in these previous publications.

2.4. Oxidation Reaction Tests. Synthetic solutions of the different aldoses, separately or in mixture, and the hydrolysates were oxidized with alkaline $\mathrm{pH}$ control over $\mathrm{Pt} / \mathrm{C}\left([\text { aldose }]_{0}=0.25 \mathrm{M}\right.$, aldose $/ \mathrm{Pt}(\mathrm{n} / \mathrm{n})=157, \mathrm{pH} 9\left(\mathrm{NaOH} 10 \mathrm{wt} \%, T=60^{\circ} \mathrm{C}\right.$, air flow 0.5 $\mathrm{L} \mathrm{min}^{-1}$ ) or in non-neutralized conditions over AuPt bimetallic catalyst $\left([\text { aldose }]_{0}=0.25 \mathrm{M}\right.$, aldose $/$ metal $=80, T=100{ }^{\circ} \mathrm{C}$, air pressure $=40 \mathrm{bar})$.

The oxidation tests over $\mathrm{Pt} / \mathrm{C}$ were carried out at atmospheric pressure and controlled $\mathrm{pH}$ of 9 in a mechanically driven stirred 500 $\mathrm{mL}$ round-bottom jacketed glass reactor. ${ }^{37}$ In a typical run, $300 \mathrm{~mL}$ of an aqueous solution of sugars and the catalyst were introduced into the reactor under $\mathrm{N}_{2}$ flow. The temperature was increased to $60{ }^{\circ} \mathrm{C}$, the $\mathrm{pH}$ of the reaction mixture was adjusted to 9 with $10 \mathrm{wt} \% \mathrm{NaOH}$, and the flow rate was switched to air $\left(0.5 \mathrm{~L} \mathrm{~min}^{-1}\right)$.

The oxidation experiments over $\mathrm{AuPt} / \mathrm{ZrO}_{2}$ were conducted batchwise in a $300 \mathrm{~mL} \mathrm{C22} \mathrm{Hastelloy} \mathrm{autoclave,} \mathrm{equipped} \mathrm{with} \mathrm{a}$ magnetically driven stirrer. ${ }^{43}$ Typically, the catalyst and $100 \mathrm{~mL}$ of an aqueous solution of carbohydrates were introduced into the reactor. After purging with Ar three times, the reaction medium was heated under Ar to $100{ }^{\circ} \mathrm{C}$, and the pressure was set at 40 bar of air.

2.5. Product Analysis. To follow the progress of the reaction, we periodically took and analyzed samples of the reaction medium. Ion chromatography (Methrom Professional IC850 equipped with the 872 extension module and 889 autosampler) was used to separate and quantify the liquid products after separation from the solid catalyst by filtration. Prior to the analysis the samples were diluted by a factor 50 to 500

Separation and analysis of monosaccharides were performed with a CarboPac PA1 $(250 * 4 \mathrm{~mm})$ column after a guard column. The column was coupled to a Pulsed Amperometer Detection (PAD). The eluent gradient was set at $2.5 \mathrm{mM} \mathrm{NaOH}$ isocratic for $45 \mathrm{~min}$ with a step to $100 \mathrm{mM} \mathrm{NaOH}$ over $5 \mathrm{~min}$ to regenerate the column, and reequilibration at $2.5 \mathrm{mM}$ for $10 \mathrm{~min}$ at a flow rate of $1 \mathrm{~mL} \mathrm{~min}^{-1}$ and a temperature of $17{ }^{\circ} \mathrm{C}$ maintained by a Pelletier effect oven.

Separation of aldarates was also performed using the CarboPac PA1 column with an eluent composed of $5 \mathrm{mM} \mathrm{NaOH}$ and $200 \mathrm{mM}$ $\mathrm{NaOAc}$, as adapted from the literature for the determination of sialic acids. $^{46}$ Precise quantification of the outcome of the oxidation reactions was made possible by analysis with the amperometric PAD detector and by comparison with authentic aldaric samples. The response of the aldaric acids on the gold electrode was much lower than the response of the sugars; moreover, the intensity of the signal was dependent on the chain length of the aldarates, the signal of $\mathrm{C5}$ aldarates being much less intense than that of C6 aldarates. Figure S1 shows the separation of the different components: arabinose, galactose, glucose, xylose, mannose, and fructose on the one hand, and galactarate, glucarate, xylarate, arabinarate, and mannarate on the other hand.

The other carboxylates formed during the reaction of glucose oxidation could also be analyzed using an IonPac AS11-HC $\left(250^{*} 4\right.$ $\mathrm{mm}$ ) column maintained at $35{ }^{\circ} \mathrm{C}$ and a suppressed conductivity detector; the $\mathrm{NaOH}$ eluent concentration increased from $2 \mathrm{mM}$ to 35 $\mathrm{mM}$ over $25 \mathrm{~min}$, followed by $100 \mathrm{mM}$ over $5 \mathrm{~min}$ to ensure flushing off of all potential contaminants. However, the conductometry does not allow the detection of noncharged species such as alcohols and aldehydes. In addition, the separation of hexarates is not possible using the AS11-HC column. Caution should be taken, because arabinarate, if formed, is coeluted with glucarate.

The total organic carbon (TOC) in solution was measured with a TOC analyzer (Shimadzu TOC-VCHS) equipped with an ASIautomatic sampler.

\section{RESULTS AND DISCUSSION}

3.1. Oxidation of Sugars Alone or As a Mixture. In our previous studies, we performed the catalytic oxidation of glucose to glucarate over $\mathrm{Pt} / \mathrm{C}$ and to glucaric acid over $\mathrm{Au}-$ $\mathrm{Pt} / \mathrm{ZrO}_{2}{ }^{37,43}$ Figure 1 reminds the temporal evolution of the concentrations of glucose, gluconic acid, and glucaric acid, as well as the TOC measure in liquid phase.

The oxidation of glucose to glucarate (glucaric acid) was clearly shown to be a process of consecutive and parallel reactions as the result of the relatively low reactivity of the primary alcohol compared with the aldehyde group. Glucose was first oxidized to gluconate (or gluconic acid), glucarate (glucaric acid) was then formed via guluronate (guluronic acid) by consecutive oxidation of the alcohol function. Many byproducts were analyzed as $\mathrm{C} 2-\mathrm{C} 4(\mathrm{di})$ acid salts or (di) acids, respectively, as the result of overoxidation and fragmentation of the $\mathrm{C} 6$ oxidized products. The consequence was also a decrease of the TOC concentration during reaction. About $10 \%$ of initial TOC was lost during reaction at $\mathrm{pH} 9$; a drastic loss of $40 \%$ was observed in the oxidation of glucose to glucaric acid, due to the larger formation of $\mathrm{CO}_{2}$, as revealed by analysis of the gas phase. ${ }^{37,43}$ 
In this work, we first examined the oxidation of the different C6 and C5 sugars that were present in the hydrolysate of pinewood. In the hydrolysate containing a total sugar concentration of $45 \mathrm{~g} \mathrm{~L}^{-1}$, mannose was the most important monomer $(44 \%)$, followed by xylose $(21 \%)$, galactose $(15 \%)$, glucose (13\%), and arabinose (7\%). The structures of the aldoses studied and mentioned in the discussion are shown in Scheme 2.

\section{Scheme 2. Structure of the Aldoses Cited in the Manuscript}
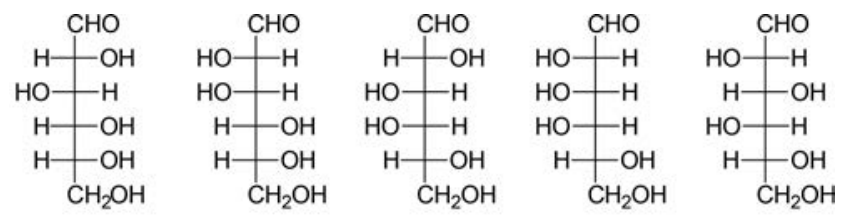

D-glucose

D-mannose
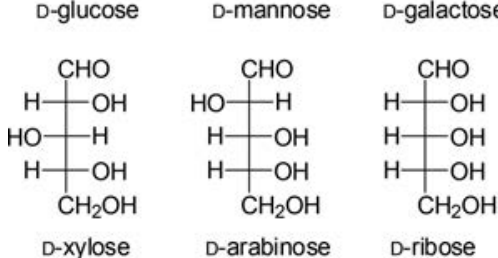

D-talose

D-idose

D-xylose

The sugars were first oxidized separately at a concentration of $0.25 \mathrm{M}$. Figure 2 depicts the results for the series of aldoses over both catalytic systems. For reasons of clarity, only the yield of the corresponding aldarate or aldaric acid is shown. The byproducts are overoxidation $\mathrm{C} 2-\mathrm{C} 4$ diacids or their salts, such as tartaric, tartronic, glyceric, glycolic, and oxalic acids. ${ }^{37,43}$

In the presence of $\mathrm{Pt} / \mathrm{C}$ at $\mathrm{pH} 9$ (Figure 2a), the initial reaction rates of formation of the aldarates were close, though it was found a little higher for arabinose oxidation. The maximum yield of aldarate was obtained after $8 \mathrm{~h}$ of reaction. It was in the range between $40 \%$ from galactose and $70 \%$ from mannose, whereas it was about $46 \%$ from glucose. It slightly decreased then upon pursuing the reaction to $24 \mathrm{~h}$.

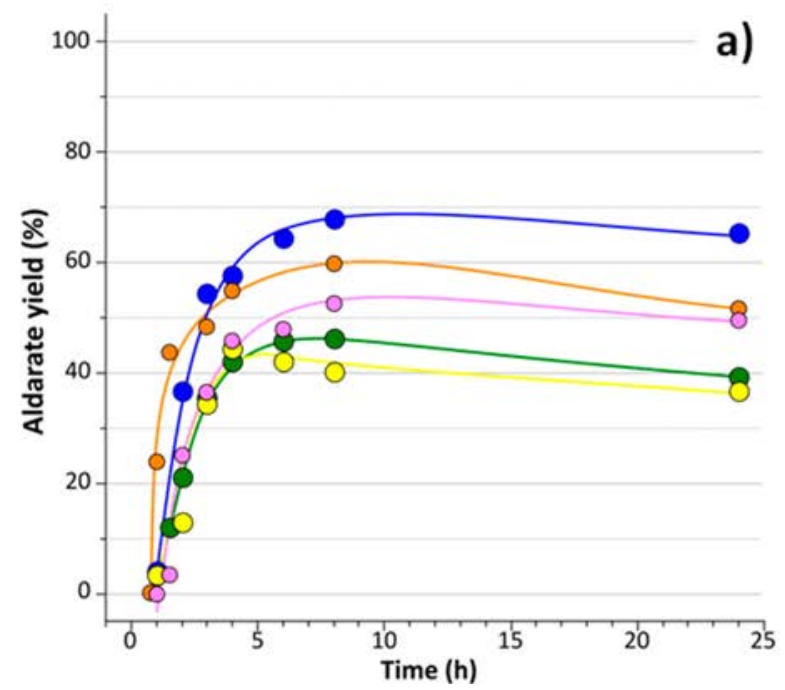

One may note that for glucose oxidation under alkaline conditions the maximum yield of glucarate (46\%) was lower when analyzed by amperometry than when analyzed by conductimetry, as given previously (54\%). ${ }^{37}$ Indeed, arabinarate which is formed during the reaction of glucose by decarboxylation (vide infra) was coeluted with glucarate on the AS11-HC column connected to the conductometer. In this study, all aldaric acids were analyzed using amperometry, which allowed us to detect decarboxylation products issued from the hexaric acids, and to give more accurate results.

In the presence of $\mathrm{Au}-\mathrm{Pt} / \mathrm{ZrO}_{2}$ under noncontrolled $\mathrm{pH}$ conditions (Figure 2b), the rates of formation of the pentaric acids were lower than the ones of the hexaric acids. The maximum yield of aldaric acid after $8 \mathrm{~h}$ was in the range from $25 \%$ (arabinose) to $60 \%$ (galactose). The overoxidation reactions leading to the decrease of the yield of aldaric acid when the reaction was prolonged were more significant than in the alkaline medium; for instance, the yield of mannaric acid decreased from $51 \%$ after $8 \mathrm{~h}$ to $29 \%$ after $24 \mathrm{~h}$.

The different aldoses, and subsequent aldonate or aldonic acid intermediates, did not display the same reactivity. These observations may be explained by the different configurations of the carbohydrates involved (Scheme 2). Such a rate effect has been reported in the literature for the catalytic oxidation of various pentoses and hexoses to the corresponding aldonates at controlled alkaline $\mathrm{pH}$ under atmospheric pressure over $\mathrm{Au}, \mathrm{Pd}$, and Pt catalysts. ${ }^{4-49}$ The sugars are present mainly in cyclic conformation (pyranose or furanose) that induces different steric hindrance of both faces depending on the configuration. Over the three catalysts, arabinose and ribose displayed higher activity than lyxose and xylose. More precisely, catalytic activity over $\mathrm{Pt}$ was higher for ribose compared to lyxose (the configuration of the $\mathrm{OH}-4$ group is different); also the configuration of the $\mathrm{OH}-2$ group influenced the activity, the rate for arabinose oxidation was higher than for ribose. The reaction rate was also influenced by the structure of the hexoses, but not in the same manner depending on the catalyst; galactose was oxidized faster than glucose over $\mathrm{Pt}$, whereas the inverse was observed over $\mathrm{Au}$. On the other hand, the

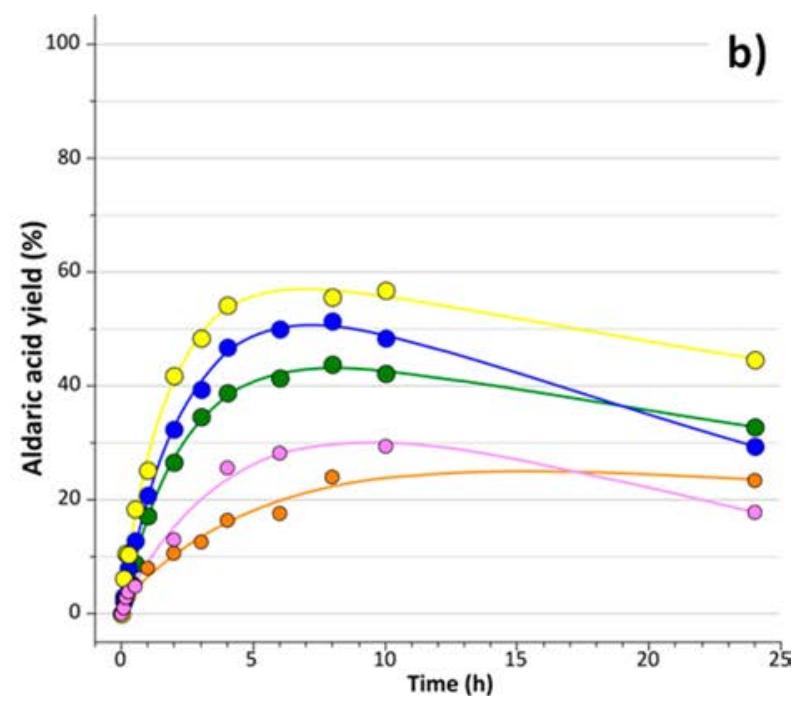

Figure 2. Yield of aldarate (aldaric acid) during oxidation of each aldose separately in the presence of (a) $\mathrm{Pt} / \mathrm{C}$ and $(\mathrm{b}) \mathrm{Au}-\mathrm{Pt} / \mathrm{ZrO}$. $\mathrm{Reaction}$ conditions: (a) $4.7 \% \mathrm{Pt} / \mathrm{C}$, [aldose $]_{0}=0.25 \mathrm{M}$, aldose $/ \mathrm{Pt}$ molar ratio $=157, \mathrm{pH} 9,60{ }^{\circ} \mathrm{C}, 0.5 \mathrm{~mL} \mathrm{~min}{ }^{-1}$ of air; (b) $3.5 \% \mathrm{Au}-3.5 \% \mathrm{Pt} / \mathrm{ZrO}{ }_{2},[\mathrm{aldose}] 0=$ $0.25 \mathrm{M}$, aldose $/ \mathrm{Au}+\mathrm{Pt}=80,100{ }^{\circ} \mathrm{C}, 40$ bar of air. Orange, arabinaric acid; pink, xylaric acid; green, glucaric acid; yellow, galactaric acid; blue, mannaric acid. 

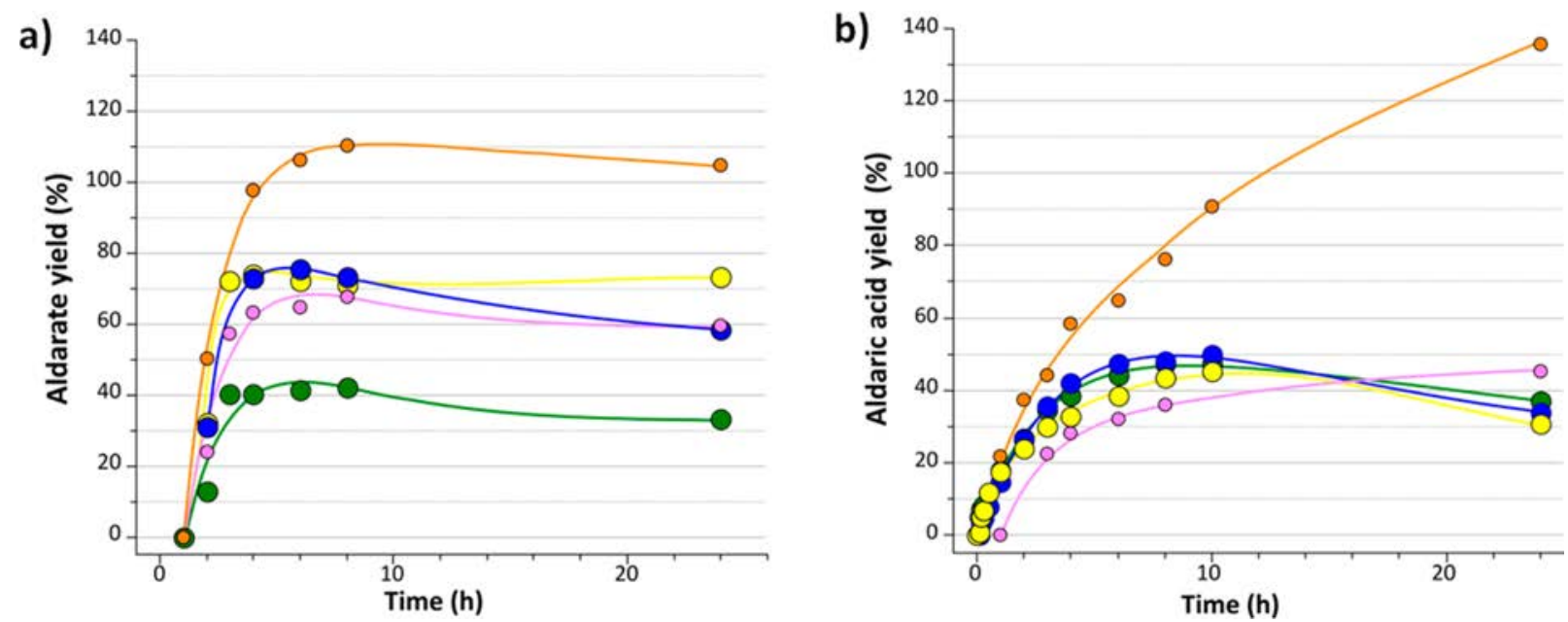

Figure 3. Evolution of yields of (a) aldarates over $\mathrm{Pt} / \mathrm{C}$ and (b) aldaric acids over $\mathrm{Au}-\mathrm{Pt} / \mathrm{ZrO}_{2}$. Reaction conditions: $(\mathrm{a}) 4.7 \% \mathrm{Pt} / \mathrm{C},[\mathrm{mannose}]_{0}=$ $[\text { glucose }]_{0}=[\text { galactose }]_{0}=[\text { xylose }]_{0}[\text { arabinose }]_{0}=0.05 \mathrm{M}$, aldose $/ \mathrm{Pt}$ molar ratio $=157, \mathrm{pH} \mathrm{9,60}{ }^{\circ} \mathrm{C}, 0.5 \mathrm{~mL} \mathrm{~min}{ }^{-1} \mathrm{of} \mathrm{air;}(\mathrm{b}) 3.5 \% \mathrm{Au}-3.5 \% \mathrm{Pt} /$ $\mathrm{ZrO}_{2},[\text { mannose }]_{0}=[\text { glucose }]_{0}=[\text { galactose }]_{0}=[\text { xylose }]_{0}[\text { arabinose }]_{0}=0.05 \mathrm{M}$, aldose $/ \mathrm{Au}+\mathrm{Pt}=80,100{ }^{\circ} \mathrm{C}, 40$ bar of air. Orange, arabinaric acid; pink, xylaric acid; green, glucaric acid; yellow, galactaric acid; blue, mannaric acid.

comparative transformation of the sugars in the absence of added base has been little explored. In the oxidation of various pentoses over three different $4 \mathrm{wt} \% \mathrm{Pt}$ catalysts in $1 \mathrm{~mL}$ vials, under the same reaction conditions $\left(90^{\circ} \mathrm{C}\right.$, about 5 bar of $\left.\mathrm{O}_{2}\right)$ the yield of pentaric acid after $8 \mathrm{~h}$ was higher when the reaction was conducted starting from arabinose and ribose (34-52\%) than from xylose $(14-29 \%) .{ }^{42}$

The reaction of an equimolar mixture of the sugars $(0.05 \mathrm{M}$ each) was then studied. The results are shown in Figure 3 under alkaline or noncontrolled $\mathrm{pH}$ conditions.

The yields of hexarates (or hexaric acids) evolved in a similar manner as when the reaction was conducted with the sugars separately; the yields observed were in the range $40-70 \%$ (Figure 3a). In contrast, the yields of pentarates (or pentaric acids) were much higher than expected from the experiments described above. Under alkaline conditions, the yield of xylarate was around 70\%, the yield of arabinarate was even $110 \%$ after $10 \mathrm{~h}$ of reaction. This observation can be explained by some terminal $\mathrm{C}-\mathrm{C}$ cleavage of the $\mathrm{C} 6$ aldarates occurring during the reaction. Under noncontrolled $\mathrm{pH}$ conditions, the effect was still more evident (Figure 3b). Arabinaric acid was continuously formed all along the reaction and the yield after $24 \mathrm{~h}$ was $135 \%$ based on the initial concentration of arabinose. The yield of xylaric acid also increased, however, at a lower rate and it attained $47 \%$ at the end of the reaction. This evolution again can be explained by decarboxylation of the terminal carbon of the diacids.

We further analyzed the distribution of the pentaric acids (Scheme 3). If one considers that no isomerization took place during reaction, and according to the different stereoisomers of the initial sugars, decarboxylation of mannose and galactose will lead to arabinaric acid, whereas glucose will lead to xylaric or arabinaric acid depending on the location of the terminal decarboxylation. Therefore, arabinaric acid will be formed in higher concentrations by decarboxylation.

Finally, during oxidation of glucose or of the synthetic mixture of the aldoses over the $\mathrm{Au}-\mathrm{Pt}$ catalyst, an unidentified peak with a very small intensity was detected at $26.5 \mathrm{~min}$, suggesting another C5 or C6 diacid. Though no fructose or mannose was detected during reaction of glucose, the formation of diacids after epimerization of the aldoses was
Scheme 3. Pentaric Acids Formed by Decarboxylation of Hexaric Acids during Catalytic Oxidation

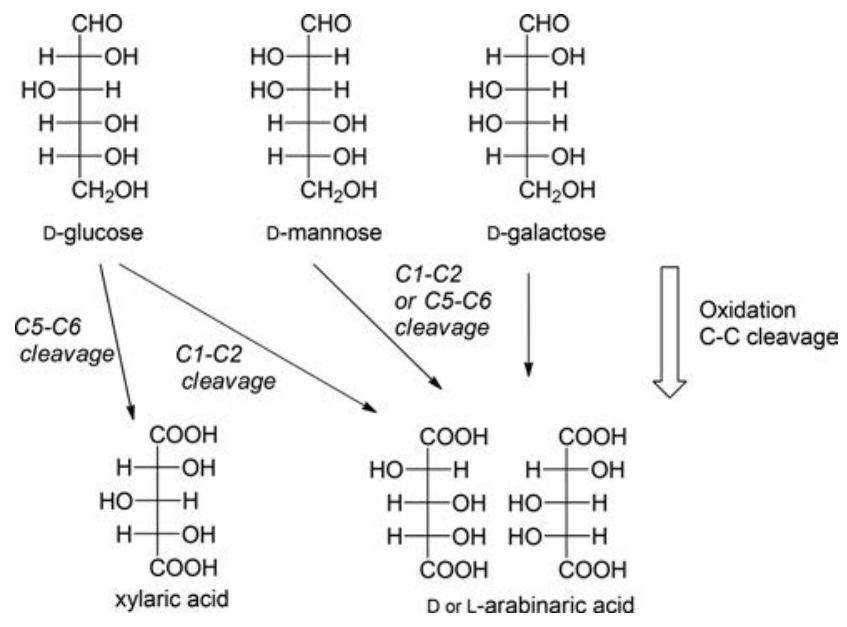

checked. The injection on the CarboPac PA1 column connected to PAD of a standard of ribaric acid, the third possible pentaric acid stereoisomer, showed a retention time close to that of arabinaric acid, which excluded this C5 diacid. The synthesis of disodium D-altrarate from D-talose (Supporting Information) also excluded altraric acid, which could be formed after epimerization of mannose or galactose. The formation of D-idaric acid via epimerization of glucose at position C5 is another possibility that we did not check because of the nonavailability.

3.b. Oxidation of Hemicellulose Hydrolysate after Various Purification Treatments. The hydrolysis of wood generated a raw hydrolysate that was purified according to several protocols. The composition of the more or less purified hydrolysates is shown in Table 1 .

After filtration to eliminate the residual solid materials, and concentration by evaporation under vacuum $\left(100 \mathrm{mbar}, 40^{\circ} \mathrm{C}\right)$ to eliminate volatile compounds (furfural and a portion of acetic acid), the acidic stream hydrolysate 1 , called $\mathrm{H} 1$ ( $\mathrm{pH} 0.7$ ) was yellow-colored and contained around $46 \mathrm{~g} \mathrm{~L}^{-1}$ monosaccharides. These are composed of a high proportion 
Table 1. Composition of the Purified Hydrolysates before the Oxidation Reaction

\begin{tabular}{|c|c|c|c|}
\hline $\begin{array}{l}\text { purification } \\
\text { steps }\end{array}$ & $\begin{array}{l}\text { filtration } \\
\text { evaporation }\end{array}$ & $\begin{array}{c}\text { hydrolysate } 2 \\
\text { filtration } \\
\text { demineralization } \\
\text { evaporation }\end{array}$ & $\begin{array}{c}\text { hydrolysate } 3 \\
\text { filtration } \\
\text { demineralization } \\
\text { evaporation GAC } \\
\text { treatment }\end{array}$ \\
\hline$\frac{[\text { glucose }]_{0}}{\left(\mathrm{~g} \mathrm{~L}^{-1}\right)}$ & 5 & 4 & 4 \\
\hline$\underset{\left(\mathrm{g} \mathrm{L}^{-1}\right)}{[\operatorname{mannose}]_{0}}$ & 22 & 15 & 13 \\
\hline$\underset{\left(\mathrm{g} \mathrm{L}^{-1}\right)}{[\text { galactose }]_{0}}$ & 8 & 6 & 5 \\
\hline $\begin{array}{l}\text { total } \\
{\left[\begin{array}{l}\text { hexoses }]_{0} \\
\left(\mathrm{~g} \mathrm{~L}^{-1}\right)\end{array}\right.}\end{array}$ & 35 & 25 & 22 \\
\hline $\begin{array}{r}{[\text { xylose }]_{0}} \\
\left(\mathrm{~g} \mathrm{~L}^{-1}\right)\end{array}$ & 5 & 4 & 4 \\
\hline $\begin{array}{c}{[\operatorname{arabinose}]_{0}} \\
\left(\mathrm{~g} \mathrm{~L}^{-1}\right)\end{array}$ & 6 & 2 & 1 \\
\hline $\begin{array}{l}\text { total } \\
{\left[\begin{array}{l}\text { pentoses }]_{0} \\
\left(\mathrm{~g} \mathrm{~L}^{-1}\right)\end{array}\right.}\end{array}$ & 11 & 6 & 5 \\
\hline $\mathrm{pH}$ & 0.7 & 10.7 & 6.5 \\
\hline $\begin{array}{r}{[\text { furfural] }} \\
\left(\mathrm{g} \mathrm{L}^{-1}\right)\end{array}$ & 0 & 0 & 0 \\
\hline$\underset{\left(\mathrm{g} \mathrm{L}^{-1}\right)}{[\mathrm{HMF}]}$ & 1.1 & 0.5 & $2.8 \times 0^{-3}$ \\
\hline $\begin{array}{l}\text { conductivity } \\
\left(\mathrm{mS} \mathrm{cm}^{-1}\right)\end{array}$ & 12.0 & $<1 \times 10^{-3}$ & $<1 \times 10^{-3}$ \\
\hline color & yellow & colorless & colorless \\
\hline
\end{tabular}

of mannose $\left(22 \mathrm{~g} \mathrm{~L}^{-1}\right)$, along with glucose $\left(5 \mathrm{~g} \mathrm{~L}^{-1}\right)$, galactose $\left(8 \mathrm{~g} \mathrm{~L}^{-1}\right)$, xylose $\left(5 \mathrm{~g} \mathrm{~L}^{-1}\right)$, and arabinose $\left(6 \mathrm{~g} \mathrm{~L}^{-1}\right)$. 5Hydroxymethylfurfural (HMF, $1.1 \mathrm{~g} \mathrm{~L}^{-1}$ ) resulting from hexoses dehydration was detected. Size Exclusion Chromatography (SEC) on the sample revealed the presence of watersoluble polymers with molecular weight above $300 \mathrm{~g} \mathrm{~mol}^{-1}$; the precise characterization of these polymers was not possible, however oligomeric sugars have been evidenced (the signature of disaccharides was observed) as well as soluble humins which were unstable and precipitated during storage (characterized by

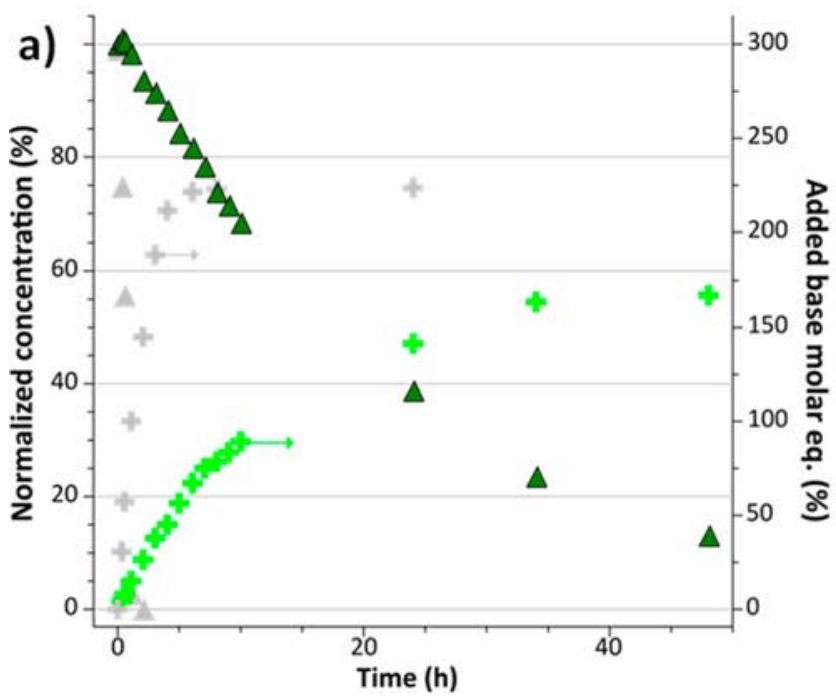

${ }^{13} \mathrm{C}$ CPMAS and ${ }^{1} \mathrm{H}$ NMR in DMSO-d6). Lignin degraded phenolics such as guaiacol and vanillin were also identified by mass spectrometry after liquid-liquid extraction using dichloromethane. Inorganic salts accounted for the relatively high conductivity of the solution $\left(12 \mathrm{mS} \mathrm{cm}^{-1}\right)$. A demineralization step by ion-exchange resins removed almost all the salts in solution (conductivity $<1 \times 10^{-3} \mathrm{mS} \mathrm{cm}^{-1}$ ). Resin treatment was also effective in discoloration, while HMF still remained (0.5 $\left.\mathrm{g} \mathrm{L}^{-1}\right)$. A colorless hydrolysate named $\mathrm{H} 2$ was thus generated. After an additional active carbon treatment the residual unsaturated compounds were completely removed, in particular HMF, to give hydrolysate $\mathrm{H} 3$. Solutions $\mathrm{H} 2$ and $\mathrm{H} 3$ were slightly diluted for the experimental tests.

The hydrolysates were examined in the oxidation reactions and the results were compared to those obtained with a synthetic solution of the same composition of sugars.

Oxidation of Hydrolysate H1. Solution $\mathrm{H} 1$ was the raw hydrolysate that was just concentrated by evaporation, which also removed furfural. The $\mathrm{pH}$ was very acidic, due to the presence of acetic acid produced from the cleavage of acetyl groups in hemicelluloses. Further, it still contained HMF $(1.1 \mathrm{~g}$ $\mathrm{L}^{-1}$ ) and the amount of inorganic salts was high as shown by the conductivity measurement. The results of oxidation of solution $\mathrm{H} 1$ under alkaline or noncontrolled $\mathrm{pH}$ conditions are shown in Figure 4. When the reaction was performed under alkaline conditions over $\mathrm{Pt} / \mathrm{C}$ (Figure $4 \mathrm{a}$ ), the $\mathrm{pH}$ of the solution was adjusted to 9 before heating under nitrogen; then, during the reaction some base was consumed to neutralize the acids and diacids formed, and maintain the $\mathrm{pH}$ constant. Figure 4a shows the total concentration of the aldoses and the added molar equivalents of $\mathrm{NaOH}$ as a function of time for the reference experiment (synthetic solution of same composition of sugars) and for hydrolysate H1. Similarly, Figure 4b shows the evolution as a function of time of total concentration of aldoses, the $\mathrm{pH}$ value, and TOC evolution for the reference solution and for $\mathrm{H} 1$.

In alkaline medium (Figure 4a), the aldoses in the synthetic solution were completely converted after $3 \mathrm{~h}$ and the final

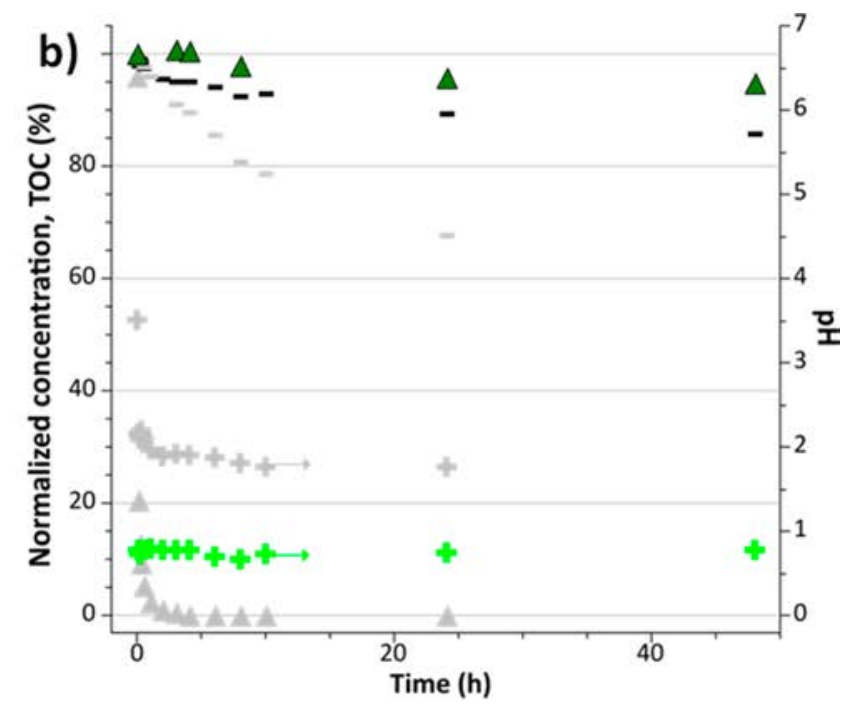

Figure 4. Evolution of the reaction during oxidation of the mixture of aldoses (gray symbols) and in hydrolysate $\mathrm{H} 1$ ( $46 \mathrm{~g} \mathrm{~L}{ }^{-1}$ aldoses) (green symbols). Reaction conditions: (a) $4.7 \% \mathrm{Pt} / \mathrm{C}$, [aldose $]_{0}=0.25 \mathrm{M}$, aldose $/ \mathrm{Pt}$ molar ratio $=157, \mathrm{pH} 9,60{ }^{\circ} \mathrm{C}, 0.5 \mathrm{~mL} \mathrm{~min}{ }^{-1}$ of air, $(\mathrm{b}) 3.5 \% \mathrm{Au}-3.5 \%$ $\mathrm{Pt} / \mathrm{ZrO}_{2}$, [aldose $] 0=0.25 \mathrm{M}$, aldose $/ \mathrm{Au}+\mathrm{Pt}=80,100{ }^{\circ} \mathrm{C}, 40$ bar of air. (a) Gray and green triangles, aldoses, gray and green plus signs, $\mathrm{NaOH}$ consumption; (b) Gray and green triangles, aldoses; gray and green plus signs, $\mathrm{pH}$, gray and green negative signs, TOC. 

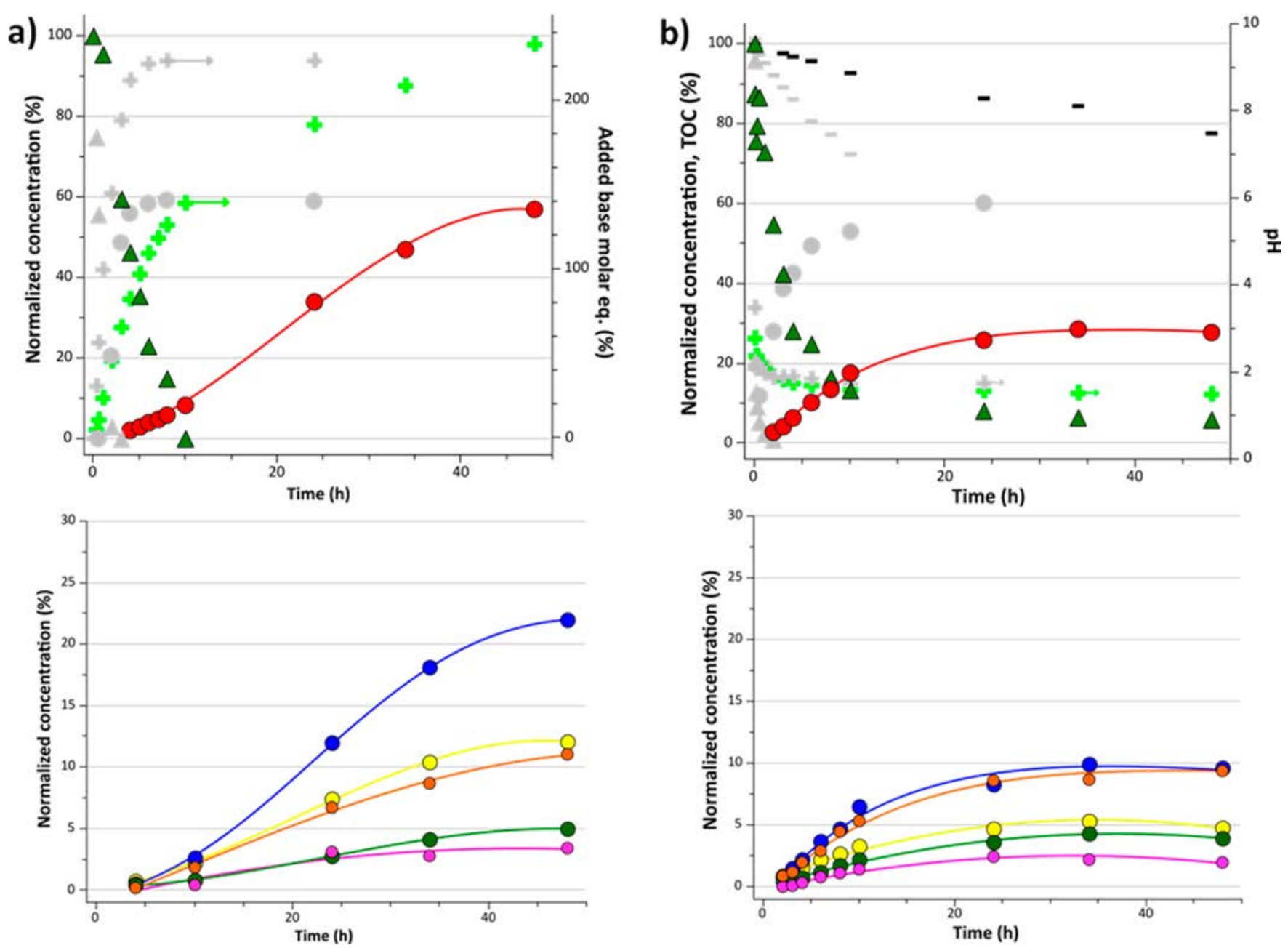

Figure 5. Oxidation of sugars in the mixture of aldoses (gray symbols) and in hydrolysate $\mathrm{H} 2\left(31 \mathrm{~g} \mathrm{~L}^{-1}\right.$ aldoses) (symbols in color). Reaction conditions: (a) $4.7 \% \mathrm{Pt} / \mathrm{C}$, [aldose $]_{0}=0.25 \mathrm{M}$, aldose $/ \mathrm{Pt}$ molar ratio $=157, \mathrm{pH} 9,60{ }^{\circ} \mathrm{C}, 0.5 \mathrm{~mL} \mathrm{~min}{ }^{-1}$ of air, $(\mathrm{b}) 3.5 \% \mathrm{Au}-3.5 \% \mathrm{Pt} / \mathrm{ZrO}{ }_{2},[\mathrm{aldose}]_{0}=$ $0.25 \mathrm{M}$, aldose $/ \mathrm{Au}+\mathrm{Pt}=80,100{ }^{\circ} \mathrm{C}, 40$ bar of air. (a) Gray and green triangles, aldoses; gray and red circles, aldarates; gray and green plus signs, $\mathrm{NaOH}$ consumption; (b) gray and green triangles, aldoses; gray and green plus signs, $\mathrm{pH}$; gray and green negative signs, TOC; (a and b) orange circles, arabinaric acid; pink circles, xylaric acid; green circles, glucaric acid; yellow circles, galactaric acid; blue circles, mannaric acid.

amount of base consumed after $48 \mathrm{~h}$ to neutralize the acids and diacids was approximately $2.25 \mathrm{~mol}$. eqv. per aldose, close to the value for glucose oxidation under the same conditions. ${ }^{37}$ After $48 \mathrm{~h}$ of reaction, final conversion of the aldoses in $\mathrm{H} 1$ was only $85 \%$, and no aldarate was detected at all. Only peaks characteristic of the aldonates were observed but not quantified and the amount of base introduced was only 1.7 mol. equiv. per aldose.

In non-neutralized medium over $\mathrm{Au}-\mathrm{Pt} / \mathrm{ZrO}_{2}$, the reaction was even worse. Conversion of the aldoses in the synthetic solution was total after $2 \mathrm{~h}$, a time close to that previously observed for glucose oxidation, ${ }^{43} \mathrm{pH}$ decreased because of the formation of the carboxylic acid functions, and TOC decreased due to the overoxidation to shorter-chain diacids. In contrast, conversion of aldoses in solution $\mathrm{H} 1$ was only $7 \%$ in hydrolysate $\mathrm{H1}, \mathrm{pH}$ and TOC remained roughly constant.

The results under both conditions point out the inhibiting effect of some of the compounds giving the color of the hydrolysate, and/or the inorganic salts in $\mathrm{H1}$ and clearly evidence the necessity to pretreat the aqueous stream before upgrading, especially for aldaric acids production.

Oxidation of Hydrolysate H2. Demineralization of the filtrated raw hydrolysate was conducted before evaporation. By adding this intermediate step to deliver solution $\mathrm{H} 2$, conductivity strongly decreased to less than $1 \mu \mathrm{s} \mathrm{cm}^{-1}$, half of the HMF was removed, and the aqueous stream became colorless, suggesting that most of the unsaturated compounds could be eliminated. The $\mathrm{pH}$ of $\mathrm{H} 2$ was over 10 because of the ion-exchange technology. Hydrolysate $\mathrm{H} 2$ was slightly diluted and contained $31 \mathrm{~g} \mathrm{~L}^{-1}$ aldoses. The results of catalytic experiments for the synthetic solution and hydrolysate $\mathrm{H} 2$ are shown in Figure 5 under both $\mathrm{pH}$ conditions.

After the addition of an intermediate demineralization pretreatment between filtration and evaporation, the kinetics of oxidation of the mixture of aldoses were accelerated, and C5 and $\mathrm{C} 6$ aldaric acids or their disodium salts were formed with relatively good yields. In alkaline medium (Figure 5a), conversion was complete after $10 \mathrm{~h}$ and the consumption of added sodium hydroxide after $48 \mathrm{~h}$ was over 2 mol. eqv. per aldose. As expected from the oxidation of sugars, mannarate concentration was the highest. At acidic $\mathrm{pH}$ (Figure $5 \mathrm{~b}$ ), the beneficial effect of demineralization was not as important. The residual HMF concentration of $0.5 \mathrm{~g} \mathrm{~L}^{-1}$ might be still too high in the stream and may have a decreasing effect on the reaction rate $(10 \mathrm{~h}$ vs $3 \mathrm{~h})$, as was clearly shown for a glucose synthetic solution. ${ }^{43}$ In addition, the concentrations of aldaric acids in the 

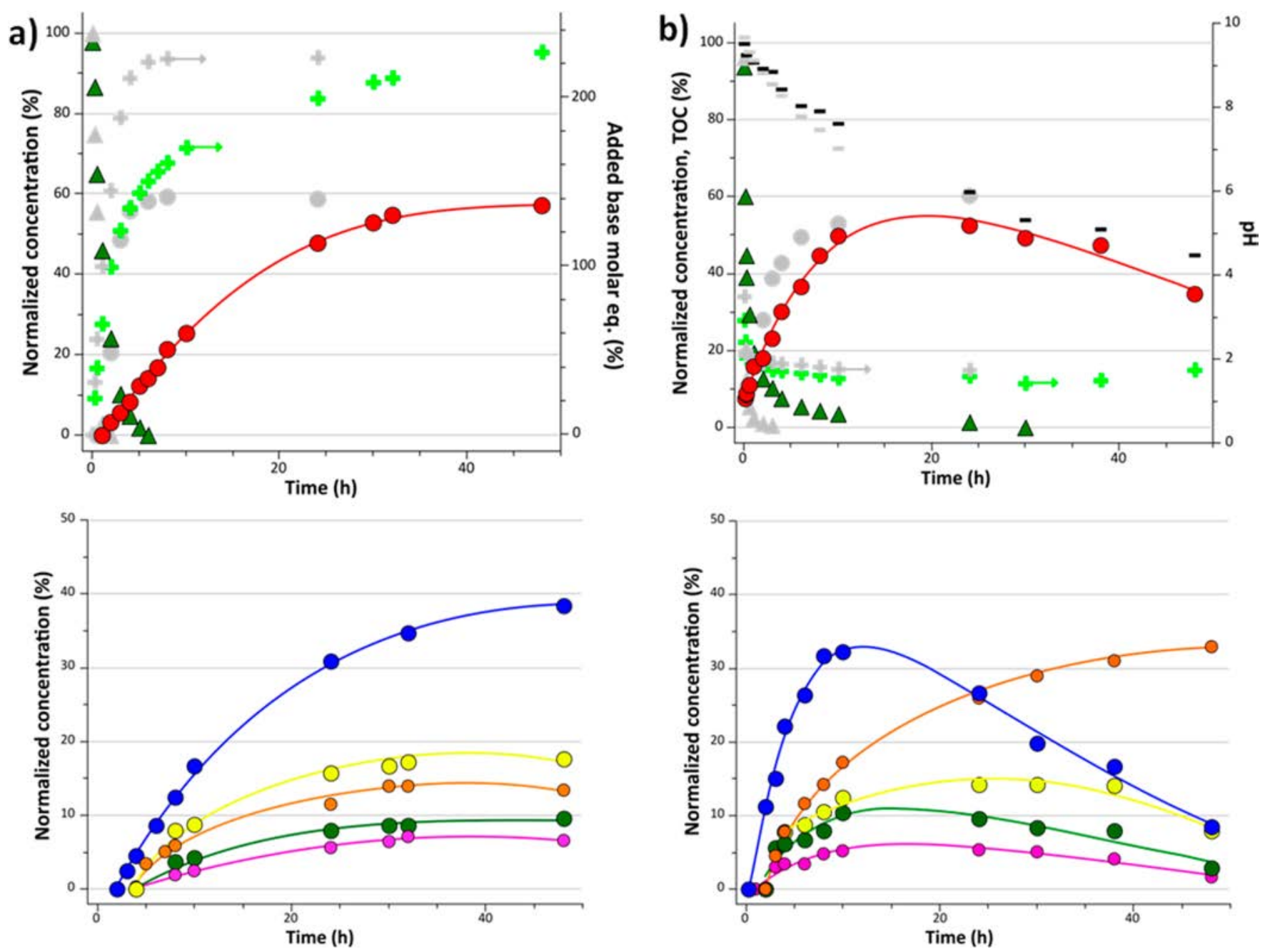

Figure 6. Oxidation of sugars in the mixture of aldoses (gray symbols) and in hydrolysate $\mathrm{H} 3\left(27 \mathrm{~g} \mathrm{~L}^{-1}\right.$ aldoses) (symbols in color). Reaction conditions: (a) $4.7 \% \mathrm{Pt} / \mathrm{C}$, [aldose $]_{0}=0.25 \mathrm{M}$, aldose $/ \mathrm{Pt}$ molar ratio $=157, \mathrm{pH} 9,60^{\circ} \mathrm{C}, 0.5 \mathrm{~mL} \mathrm{m^{-1 }}$ of air; (b) $3.5 \% \mathrm{Au}-3.5 \% \mathrm{Pt} / \mathrm{ZrO}$, $[$ aldose $] 0=$ $0.25 \mathrm{M}$, aldose $/ \mathrm{Au}+\mathrm{Pt}=80,100{ }^{\circ} \mathrm{C}, 40 \mathrm{bar}$ of air. (a) Gray and green triangle, aldoses; gray and red circle, aldarates; gray and green plus signs, $\mathrm{NaOH}$ consumption; (b) gray and green triangles, aldoses; gray and green plus signs, $\mathrm{pH}$; gray and green negative signs, TOC; (a and b) orange circles, arabinaric acid; pink circles, xylaric acid; green circles, glucaric acid; yellow circles, galactaric acid; blue circles, mannaric acid.
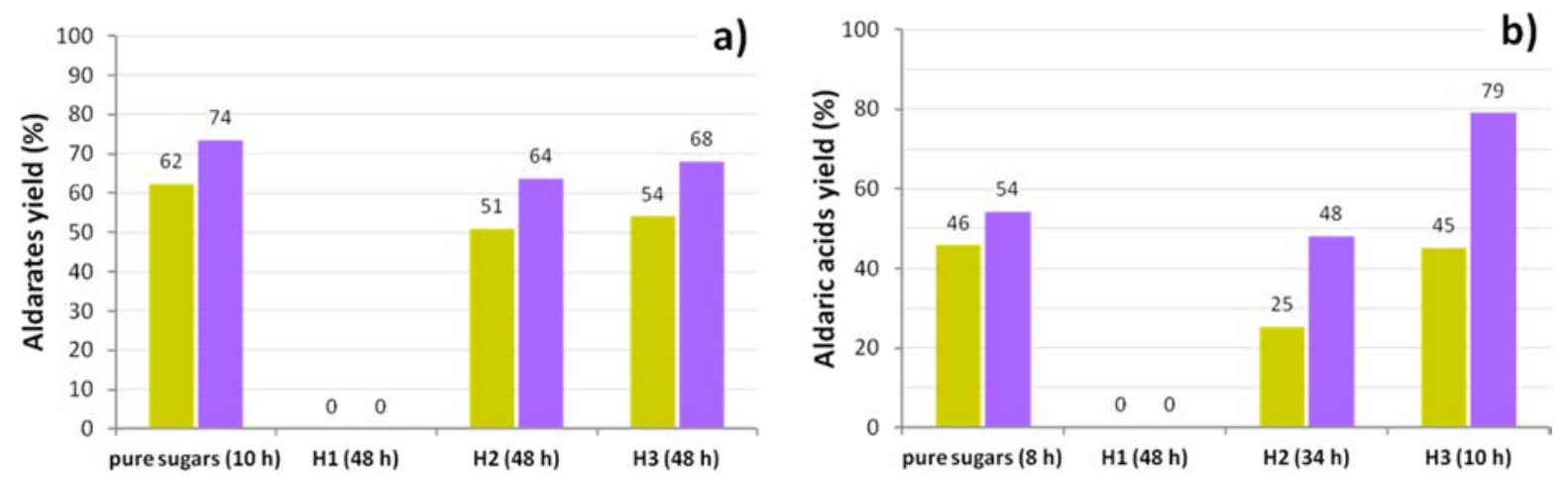

Figure 7. Maximum yields of aldarates (aldaric acids) and time to attain that yields during oxidation of synthetic solutions of sugars and hydrolysates $\mathrm{H} 1-\mathrm{H} 3$. Reaction conditions: (a) $4.7 \% \mathrm{Pt} / \mathrm{C}$, [aldose $]_{0}=0.25 \mathrm{M}$, aldose $/ \mathrm{Pt}$ molar ratio $=157, \mathrm{pH} \mathrm{9,60}{ }^{\circ} \mathrm{C}, 0.5 \mathrm{~mL} \mathrm{~min}{ }^{-1} \mathrm{of}$ air, $(\mathrm{b}) 3.5 \% \mathrm{Au}-3.5 \%$ $\mathrm{Pt} / \mathrm{ZrO}_{2}$, aldose $] 0=0.25 \mathrm{M}$, aldose $/ \mathrm{Au}+\mathrm{Pt}=80,100^{\circ} \mathrm{C}, 40$ bar of air. Yellow-green, $\mathrm{C} 6$ aldarates or aldaric acids; purple, $\mathrm{C} 5$ aldarates or aldaric acids.

final solution were in agreement with the previous observations (Figure 3) over $\mathrm{Au}-\mathrm{Pt} / \mathrm{ZrO}_{2}$ with synthetic solution of aldoses, i.e., arabinaric acid concentration was high due to decarboxylation of hexaric acids.
Oxidation Profile of Hydrolysate H3. A final treatment by active carbon significantly improved the purity of the hydrolysate. It still retained some inhibiting unsaturated compounds, such as HMF whose concentration dropped to 
$0.02 \mathrm{mM}$, i.e. $10^{-4} \mathrm{~mol}$. eqv. per total aldose. The results obtained during oxidation of $\mathrm{H} 3$ are shown in Figure 6.

After treatment with granular activated carbon GAC, the reaction rates of oxidation of the aldoses in the hydrolysate were greatly improved and the diacids were also formed much faster, especially over $\mathrm{Au}-\mathrm{Pt} / \mathrm{ZrO}_{2}$. Indeed, under these noncontrolled $\mathrm{pH}$ conditions, the recorded data were very close to those observed during oxidation of the synthetic mixture. The concentration of arabinaric acid represented more than $32 \%$ of the aldaric acids after $48 \mathrm{~h}$, although the initial concentration of arabinose was only $7 \%$. This result shows again that decarboxylation of C6 diacids was very important using this catalytic system; arabinaric acid was formed, and therefore the TOC value decreased significantly.

Under both $\mathrm{pH}$ conditions, the main diacid detected was mannaric acid, consistent with the fact that mannose was the main aldose in the aqueous stream.

Finally, the global yields of hexarates (hexaric acids) and pentarates (pentaric acids) after oxidation of each purified hydrolysate were compared to those calculated from the oxidation of the synthetic solution with the same distribution of aldoses (Figure 7).

Elimination of furfural by evaporation was not sufficient to allow production of aldaric acids from $\mathrm{H} 1$. After demineralization, which partly eliminated unsaturated compounds and inorganic salts, moderate yields could be obtained at the condition of significant prolonging reaction time. Oxidation rates of sugars in the most purified $\mathrm{H} 3$ stream were much faster, showing that an active carbon treatment seems to be an indispensable step. These results are in good agreement with previous results on the effect of impurities on oxidation of glucose to the diacids. ${ }^{37,43}$ Lower reaction rates were observed in the presence of furfural, 5-hydroxymethylfurfural, lignin residues or guaiacol. In the present work, after $10 \mathrm{~h}$, a mixture of hexaric and pentaric acids was obtained with yields close to those of the synthetic solution of pure sugars. The yields of hexarates and pentarates were $54 \%$ and $68 \%$, respectively, over $\mathrm{Pt} / \mathrm{C}$; the yields of hexaric and pentaric acids were 45 and $79 \%$, respectively, over $\mathrm{Au}-\mathrm{Pt} / \mathrm{ZrO}_{2}$. Previous studies showed that $\mathrm{Au}-\mathrm{Pt} / \mathrm{ZrO}_{2}$ catalysts could be recycled in batch reactor with no significant efficiency loss for glucose oxidation to glucaric acid, and they were stable over at least 1 week in a trickle-bed reactor. ${ }^{43}$ Further study should also verify the long-term stability for the purified hydrolysates.

\section{CONCLUSIONS}

The high amount of hemicelluloses content of softwood offers significant potential for new biomass-based products. Prehydrolysis of softwood biomass prior to Kraft cooking provides a stream rich in the sugar components of hemicellulosic polymers and some undesired residues. The oxidation protocol studied for glucose oxidation to glucaric acid was successfully transferred to synthetic solutions of the series of pure aldoses present in the hydrolysate, and then to the hydrolysate. The oxidation of more or less purified hydrolysates confirmed the inhibitory ability of some of the residual compounds that were observed with glucose. After complete removal of inorganic salts and unsaturated compounds by a combined process consisting of filtration, demineralization, evaporation, and active carbon treatments to purify the hydrolysate, yields of aldarates under alkaline conditions over $\mathrm{Pt} / \mathrm{C}$ or of aldaric acids over $\mathrm{Au}-\mathrm{Pt} / \mathrm{ZrO}_{2}$ were close to those obtained in synthetic solutions of pure sugars.
To enable the utilization of sugar components in softwood hydrolysate, we have to eliminate most of the contaminants from hydrolysate.

\section{AUTHOR INFORMATION \\ Corresponding Author}

E-mail: michele.besson@ircelyon.univ-lyon1.fr. Phone: +33 472445358. Fax: +33 472445399 .

\section{ORCID}

Michèle Besson: 0000-0003-0024-5676

Notes

The authors declare no competing financial interest.

\section{ACKNOWLEDGMENTS}

The authors acknowledge financial support from the Fonds Unique Intermistériel (FUI Polywood) and gratefully acknowledge AXELERA for support. INP-Pagora (France) is gratefully acknowledged for providing the raw hydrolysate.

\section{REFERENCES}

(1) Ebringerova, A. Structural diversity and application potential of hemicelluloses. Macromol. Symp. 2005, 232, 1-12.

(2) Hansen, N. M. L.; Plackett, D. Sustainable films and coatings from hemicellulose: a review. Biomacromolecules 2008, 9, 1493-1505.

(3) Singh, V.; Kumari, P.; Pandey, S.; Narayan, T. Removal of chromium (VI) using poly(methylacrylate) functionalized guar gum. Bioresour. Technol. 2009, 100, 1977-1982.

(4) Thakur, S.; Chauhan, G. S.; Ahn, J. H. Synthesis of aryloyl guar gum and its hydrogel materials for use in the slow release of L-DOPA and L-tyrosine. Carbohydr. Polym. 2009, 76, 513-520.

(5) Nypelö, T.; Laine, C.; Aoki, M.; Tammelin, T.; Henniges, U. Etherification of wood-based hemicelluloses for interfacial activity. Biomacromolecules 2016, 17, 1894-1901.

(6) Helmerius, J.; von Walter, J. V.; Rova, U.; Berglund, K. A.; Hodge, D. B. Impact of hemicellulose pre-extraction for bioconversion on birch kraft pulp properties. Bioresour. Technol. 2010, 101, 59966005.

(7) Moshkelani, M.; Marinova, M.; Perrier, M.; Paris, J. The forest biorefinery and its implementation in the pulp and paper industry: Energy overview. Appl. Therm. Eng. 2013, 50, 1427-1436.

(8) Hamaguchi, M.; Kautto, J.; Vakkilainen, E. Effects of hemicellulose extraction on the kraft pulp mill operation and energy use: Review and case study with lignin removal. Chem. Eng. Res. Des. 2013, 91, 1284-1291.

(9) Mäki-Arvela, P.; Salmi, T.; Holmbom, B.; Willför, S.; Murzin, D. Y. Synthesis of sugars by hydrolysis of hemicelluloses-A review. Chem. Rev. 2011, 111, 5638-5666.

(10) Boucher, J.; Chirat, C.; Lachenal, D. Comparison between acid hydrolysis and two-step autohydrolysis for hemicellulosic ethanol production. Cellulose Chem. Technol. 2015, 49, 303-308.

(11) Bozell, J. J.; Petersen, G. R. Technology development for the production of biobased products from biorefinery carbohydrates-the US Department of Energy's “Top 10” revisited. Green Chem. 2010, 12, 539-554.

(12) Aury, S.; Rubini, P.; Gerardin, C.; Selve, C. Amphiphilic amide derivatives of $\mathrm{D}$-glucaric acid synthesis and complexing properties toward lanthanide (III) Ions. Eur. J. Org. Chem. 2004, 9, 2057-2066. 
(13) Kiely, D. E.; Chen, L.; Lin, T. Hydroxylated nylons based on unprotected esterified D-glucaric acid by simple condensation reactions. J. Am. Chem. Soc. 1994, 116, 571-578.

(14) Smith, T. N.; Hash, K.; Davey, C. L.; Mills, H.; Williams, H.; Kiely, D. E. Modifications in the nitric acid oxidation of D-glucose. Carbohydr. Res. 2012, 350, 6-11.

(15) Okada, D. R.; Johnson, B. G.; Liu, Z.; Hocherman, S. D.; Khaw, B.; Okada, R. D. Early detection of infarct in reperfused canine myocardium using 99mTc-Glucarate. J. Nucl. Med. 2004, 45, 655-664.

(16) Andrews, M. A.; Figuly, G. D.; Chapman, J. S.; Hunt, T. W.; Glunt, C. D.; Rivenbark, J. A.; Chenault, H. K. Antimicrobial hydrogels formed by crosslinking polyallylamine with aldaric acid derivatives. $J$. Appl. Polym. Sci. 2011, 119, 3244-52.

(17) Mehtiö, T.; Toivari, M.; Wiebe, M. G.; Harlin, A.; Penttilä, M.; Koivula, A. Production and applications of carbohydrate-derived sugar acids as generic biobased chemicals. Crit. Rev. Biotechnol. 2016, 36, 904-916.

(18) Kiely, D. E.; Chen, L.; Lin, T. Synthetic polyhydroxypolyamides from galactaric, xylaric, D-glucaric, and D-mannaric acids and alkylidenediamine monomers: some comparisons. J. Polym. Sci., Part A: Polym. Chem. 2000, 38, 594-603.

(19) Kiely, D. E.; Vishwanathan, A.; Jarman, B. P.; Manley-Harris, M. Synthesis of poly(galactaramides) from alkylene-and substituted alkylidenediammonium galactarates. J. Carbohydr. Chem. 2009, 28, $348-356$.

(20) Hashimoto, K.; Wibullucksanakul, S.; Matsuura, M.; Okada, M. Macromolecular synthesis from saccharic lactones. Ring-opening polyaddition of D-glucaro- and D-mannaro-1,4:6,3-dilactones with alkylenediamines. J. Polym. Sci., Part A: Polym. Chem. 1993, 31, 31413149.

(21) Kiely, D. E.; Chen, L.; Lin, T.-H. Synthetic polyhydroxypolyamides from galactaric, xylaric, D-glucaric, and D-mannaric acids and alkylenediamine monomers-some comparisons. J. Polym. Sci., Part A: Polym. Chem. 2000, 38, 594-603.

(22) Kiely, D. E. Carbohydrate diacids: potential as commercial chemicals and hydrophilic polyamide precursors. ACS Symp. Ser. 2001, $784,64-80$.

(23) Henkensmeier, D.; Abele, B. C.; Candussio, A.; Thiem, J. Synthesis, characterization and degradability of polyamides derived from aldaric acids and chain end functionalized polydimethylsiloxanes. Polymer 2004, 45, 7053-7059.

(24) Mehltretter, C. L.; Rist, C. E. Sugar oxidation - saccharic and oxalic acids by the nitric acid oxidation of dextrose. J. Agric. Food Chem. 1953, 1, 779-783.

(25) Pamuk, V.; Yılmaz, M.; Alıcılar, A. The preparation of Dglucaric acid by oxidation of molasses in packed beds. J. Chem. Technol. Biotechnol. 2001, 76, 186-190.

(26) Kiely, D. E.; Carter, A.; Shrout, D. P. Oxidation process, US $5599977,1997$.

(27) Kiely, D. E.; Ponder, G. Nitric acid removal from oxidation products, US $6049004,2000$.

(28) Kiely, D. E.; Hash, K. R. Method of oxidation using nitric acid, US 7692041, 2010.

(29) Carpenter, C. A.; Hardcastle, K. I.; Kiely, D. E. Modifications in the nitric acid oxidation of D-mannose: X-ray crystal structure of $N, N^{\prime}$ dimethyl D-mannaramide. Carbohydr. Res. 2013, 376, 29-36.

(30) Hinton, M. R.; Manley-Harris, M.; Hardcastle, K. I.; Kiely, D. E. Pentaric acids and derivatives from nitric acid-oxidized pentoses. J. Carbohydr. Chem. 2013, 32, 68-85.

(31) Merbouh, N.; Bobbitt, J. M.; Brückner, C. J. 4-AcNH-TEMPOcatalyzed oxidation of aldoses to aldaric acids using chlorine or bromine as terminal oxidants. J. Carbohydr. Chem. 2002, 21, 65-77.

(32) Besson, M.; Gallezot, P. Oxidation of Carbohydrates on Metal Catalysts. In Fine Chemicals through Heterogeneous Catalysis; Sheldon, R. A., van Bekkum, H., Eds.; Wiley-VCH, Weinheim, Germany, 2001; pp 507-518.

(33) Mehltretter, C. L.; Rist, C. E.; Alexander, B. H. Process for the preparation of D- glucosaccharic acid. US 2472 168, 1949.
(34) Kunz, M.; Schwarz, A.; Kowalczyk, J. Method and apparatus for producing di- and more highly oxidized carboxylic acids. US $5772013,1998$.

(35) Dirkx, J. M. H.; van der Baan, H. S. The oxidation of glucose with platinum on carbon as catalyst. J. Catal. 1981, 67, 1-13. Dirkx, J. M. H.; van der Baan, H. S. The oxidation of gluconic acid with platinum on carbon as catalyst. J. Catal. 1981, 67, 14-20.

(36) Önal, Y.; Schimpf, S.; Claus, P. Structure sensitivity and kinetics of D-glucose oxidation to D-gluconic acid over carbon-supported gold catalysts. J. Catal. 2004, 223, 122-133.

(37) Derrien, E.; Marion, P.; Pinel, C.; Besson, M. Influence of residues contained in softwood hemicellulose hydrolysates on the catalytic oxidation of glucose to glucarate in alkaline aqueous solution. Org. Process Res. Dev. 2016, 20, 1265-1275.

(38) Jin, X.; Zhao, M.; Vora, M.; Shen, J.; Zeng, C.; Yan, W.; Thapa, P. S.; Subramaniam, B.; Chaudhari, R. V. Synergistic effects of bimetallic $\mathrm{PtPd} / \mathrm{TiO}_{2}$ nanocatalysts in oxidation of glucose to glucaric acid: Structure dependent activity and selectivity. Ind. Eng. Chem. Res. 2016, 55, 2932-2945.

(39) Solmi, S.; Morreale, C.; Ospitali, F.; Agnoli, S.; Cavani, F. The oxidation of D-glucose to glucaric acid using $\mathrm{Au} / \mathrm{C}$ catalysts. ChemCatChem 2017, 9, 2797-2806.

(40) Boussie, T. R; Dias, E. L.; Fresco, Z. M.; Murphy, V. J.; Shoemaker, J.; Archer, R.; Jiang, H. Production of adipic acid and derivatives from carbohydrate-containing materials, WO 2010/144862, 2010

(41) Murphy, V. J.; Shoemaker, J.; Zhu, G.; Archer, R.; Salem, G. S.; Dias, E. L. Catalyst comprising platinum and gold nanoparticles and its use for oxidation of glucose and preparation method of such a catalyst. WO 2011/155964, 2011

(42) Boussie, T. R.; Dias, E. L.; Fresco, Z.; Murphy, V. J. Production of glutaric acid and derivatives from carbohydrate-containing materials. WO 2010/144871, 2010.

(43) Derrien, E.; Mounguengui Diallo, M.; Perret, N.; Marion, P.; Pinel, C.; Besson, M. Aerobic oxidation of glucose to glucaric acid under alkaline-free conditions: Au-based bimetallic catalysts and the effcet of residues in a hemicellulose hydrolysate. Ind. Eng. Chem. Res. 2017, 56, 13175-13189.

(44) Smith, T. N.; Hash, K.; Davey, C.-L.; Mills, H.; Williams, H.; Kiely, D. E. Modifications in the nitric acid oxidation of D-glucose. Carbohydr. Res. 2012, 350, 6-13.

(45) Takenaka, M.; Yan, X.; Ono, K.; Yoshida, M.; Nagata, T.; Nakanishi, T. Caffeic acid derivatives in the roots of yacon (Smallanthus sonchifolius). J. Agric. Food Chem. 2003, 51, 793-796.

(46) Jorge, P.; Abdul-Wajid, A. Sialyl-Tn-KLH, glycoconjugate analysis and stability by high-pH anio-exchange chromatography with pulsed amperometric detection (HPAE-PAD). Glycobiology 1995, 5, 759-764.

(47) de Wit, G.; de Vlieger, J. J.; Kock-van Dalen, A. C.; Heus, R.; Laroy, R.; van Hengstum, A. J.; Kieboom, A. P. G.; van Bekkum, H. Catalytic dehydrogenation of reducing sugars in alkaline solution. Carbohydr. Res. 1981, 91, 125-138.

(48) Mirescu, A.; Prüsse, U. A new environmental friendly method for the preparation of sugar acids via catalytic oxidation on gold catalysts. Appl. Catal., B 2007, 70, 644-652.

(49) Venema, F. R; Peters, J. A.; van Bekkum, H. Platinum-catalyzed oxidation of aldopentoses to aldaric acids. J. Mol. Catal. 1992, 77, 7585 